\section{RMD Open}

Rheumatic \&

Musculoskeletal Diseases

To cite: Calabrese $L$, Nieman DC. Exercise, infection and rheumatic diseases: what do we know?. RMD Open 2021;7:e001644. doi:10.1136/ rmdopen-2021-001644

Received 19 March 2021 Revised 4 May 2021 Accepted 4 May 2021
Check for updates

(c) Author(s) (or their employer(s)) 2021. Re-use permitted under CC BY-NC. No commercial re-use. See rights and permissions. Published by BMJ.

${ }^{1}$ Rheumatology/Immunology, Cleveland Clinic, Cleveland, Ohio, USA

${ }^{2}$ Department of Biology, Human Performance Laboratory, Appalachian State University, Boone, North Carolina, USA

Correspondence to Dr Leonard Calabrese; calabrl@ccf.org

\title{
Exercise, infection and rheumatic diseases: what do we know?
}

\author{
Leonard Calabrese (D) , ${ }^{1}$ David C Nieman ${ }^{2}$
}

\section{PHYSICAL ACTIVITY GUIDELINES AND HEALTH BENEFITS}

In recent years, there has been an increased focus on physical activity, a general term referring to bodily movement resulting in energy expenditure, and exercise, a form of physical activity which is structured, repetitive with an objective of promoting physical fitness for patients with rheumatic diseases. Guidelines for physical activity have been developed to promote health benefits from physical activity in the general population by the World Health Organization (WHO) ${ }^{1}$ and the US Department of Health and Human Services (HHS), ${ }^{2}$ and by the EULAR for people with inflammatory arthritis and osteoarthritis. ${ }^{3}$

WHO, HHS and EULAR physical activity guidelines are consistent in recommending that adults should (1) move more and sit less throughout the day; (2) aim for at least 150-300 min a week of moderate-intensity or $75-150 \mathrm{~min}$ a week of vigorous-intensity aerobic physical activity; (3) engage in whole body muscle-strengthening activities on 2 or more days a week. These guidelines also support that additional health benefits are experienced by engaging in physical activity beyond the equivalent of $300 \mathrm{~min}$ of moderate-intensity physical activity a week. Patients with rheumatic diseases have much to gain by following these guidelines, especially in light of data indicating that they are less active compared with healthy controls. ${ }^{34}$

The physiological and health benefits of regular physical activity are numerous and have well-documented effects on aerobic capacity, strength and function, mental health, the ageing process, obesity, metabolic syndrome, risk for chronic diseases such as diabetes mellitus, cancer and cardiovascular disease, arthritis and bone and joint health. ${ }^{256}$ A recent focus has been to 'move more and sit less' due to the increasing awareness that the avoidance of sedentary behaviour is critical for long term health. ${ }^{278}$ Federal exercise guidelines now emphasise that exercise does not have to be prolonged to be beneficial but that frequent small doses work just as well. ${ }^{2}$ This shift from the former rigid exercise prescription to the current lifestyle approach is expected to broaden compliance in the general population.

In the rheumatological literature, recent reviews ${ }^{9}$ and the EULAR guidelines ${ }^{3}$ emphasise many of the traditional benefits from aerobic and strength training including improved cardiorespiratory and musculoskeletal fitness, cardiovascular health, bone health as well as disease specific benefits such as reduced disease activity and pain, and improved quality of life, sleep and mental health.

Largely unexplored in the rheumatological literature is another axis of the biological effects associated with physical activity and exercise, namely the immunological effects. The field of exercise immunology is relatively new with $90 \%$ of publications reported after $1990 .^{10}$ The exercise immunology literature is growing rapidly and we are beginning to understand the broad effects of physical activity and training on the integrated immune response. These include exerciseinduced influences on both innate and adaptive immune limbs, immune surveillance, acute and chronic inflammation and the trajectory of immunosenescence. ${ }^{10-15}$

From a clinical perspective, one of the most intriguing and potentially important domains of physical activity and exercise is its effects on susceptibility to infection. ${ }^{10}$ Despite the fact that patients with inflammatory rheumatic diseases are particularly susceptible to infectious complications due to the disease process and immunomodulatory therapies, there is a paucity of literature exploring the potential utility of exercise training with the explicit purpose of lowering infectious risks.

This editorial briefly explores the exercise immunology literature with an emphasis on the evidence that moderate exercise training is associated with reduced infectious disease 


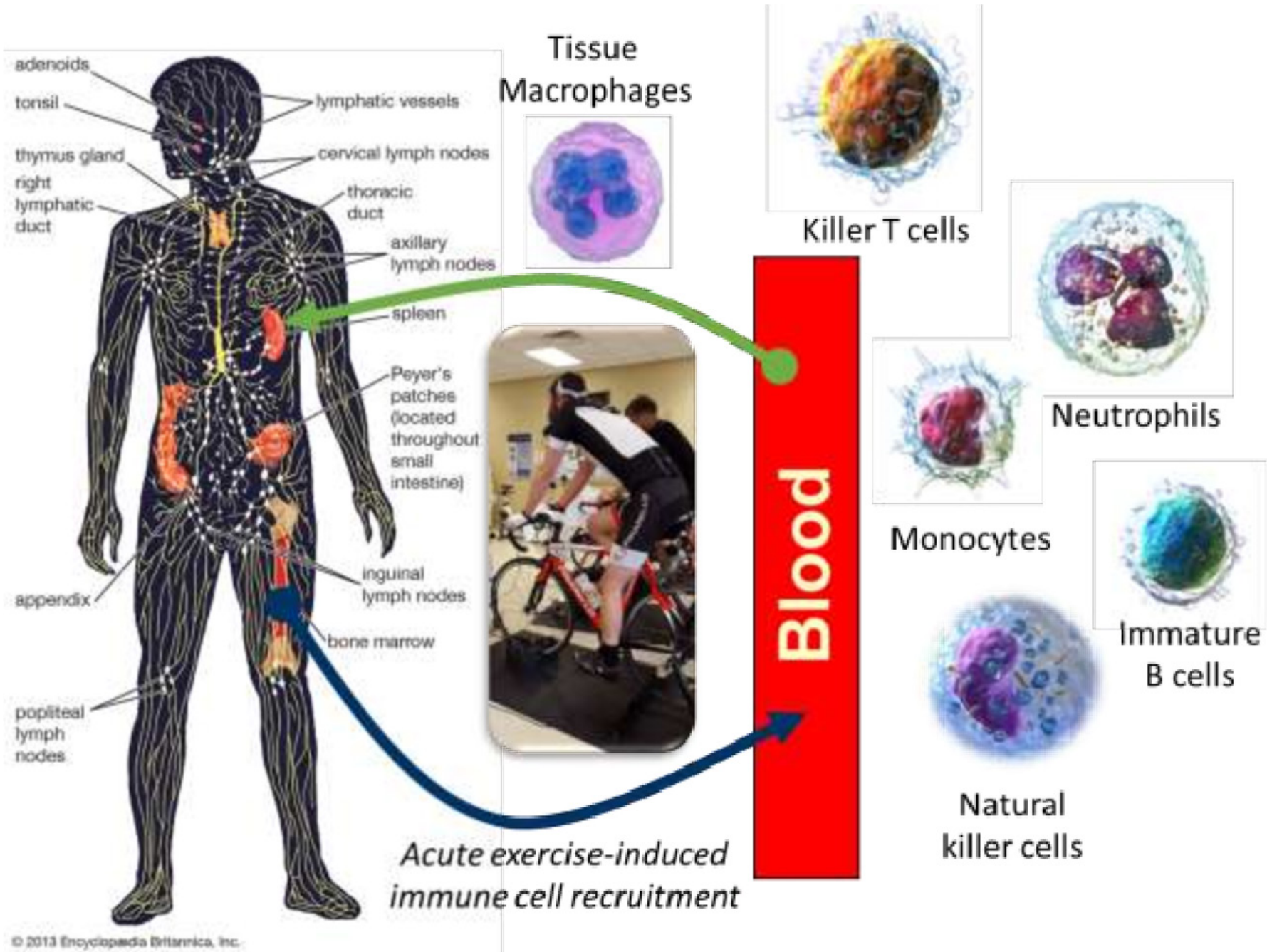

Figure 1 Exercise stimulates the ongoing exchange of leucocytes between the lymphoid tissues and the blood compartment and the activation of tissue macrophages. Cell art work: Blausen.com staff (2014). 'Medical gallery of Blausen Medical 2014'. WikiJournal of Medicine 1 (2). DOI:10.15347/wjm/2014.010. ISSN 2002-4436.

risks and systemic inflammation and proposes a research agenda to explore this unchartered field.

\section{THE IMMUNE RESPONSE TO EXERCISE}

The immune system reacts quickly and robustly to acute exercise bouts with the magnitude and nature of the response related to the workload intensity and duration. ${ }^{10} 1116$ Specific types of immune cells with high effector and cytotoxic functions are recruited from peripheral lymphoid tissues into the blood compartment during exercise bouts. ${ }^{10} 16$ These include neutrophils, monocytes, natural killer (NK) cells, cytotoxic T cells, TCR- $\gamma \delta$ T cells and immature B cells (figure 1). During exercise recovery, a rapid egress ensues consisting of lymphocytes and non-classical monocytes that exhibit phenotypes with increased effector and tissue migration functions. ${ }^{16}$ The mobilisation of immune cells with exercise is due to many factors including increased haemodynamic forces, hormone production, body temperature and cytokine levels.
Both animal and human studies support the role of exercise in augmenting the trafficking of immune cells through the lymphoid and peripheral tissues and blood and lymph compartments. ${ }^{10} 16$ The transient exerciseinduced recirculation of immune cells has the capacity to enhance immunosurveillance and host protection against pathogens. ${ }^{16}$ Antiviral activity of tissue macrophages is also stimulated in response to exercise. ${ }^{10}$ Exercise promotes the recirculation of immunoglobulins and the production of anti-inflammatory cytokines such as IL-10 and IL-1ra. During moderate-to-vigorous exercise, the muscle myokine IL-6 is produced and released and in distinction to its classical role as a driver of the inflammatory response appears to support numerous beneficial metabolic and immunoregulatory roles. ${ }^{10}{ }^{11}$ Within the bone marrow, mechanical stimulation induced by exercise augments the supply of lymphoid progenitors for specific types of immune cells including dendrites and T, B and NK lymphocytes. ${ }^{17}$ This exercise-generated effect may help counter the typical age-related decrease 


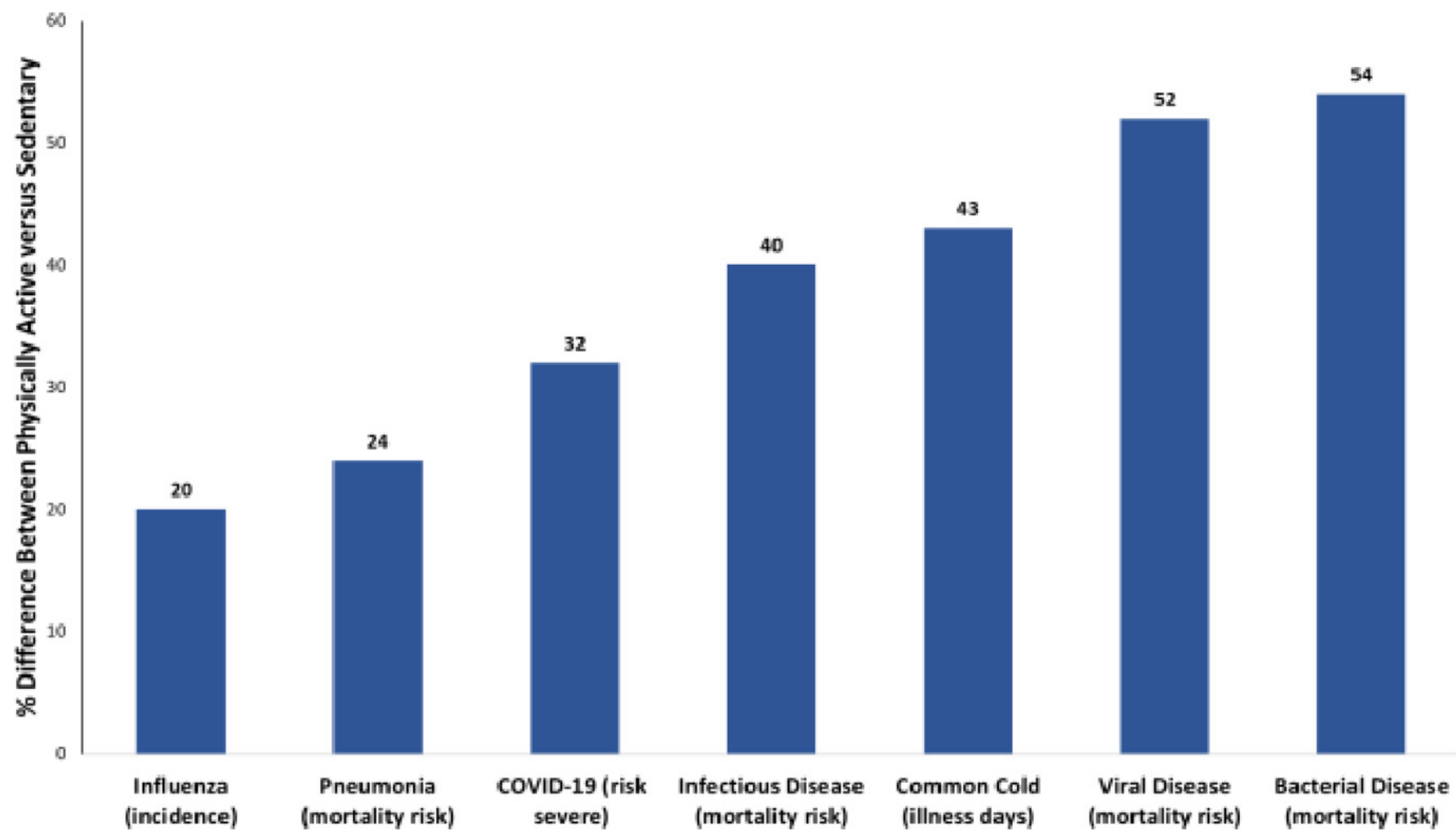

Figure 2 The percentage difference in infectious disease incidence and mortality rates between physically active and inactive adults. ${ }^{10} 1218$ 20-23 Near-daily physical activity compared with inactivity has been linked to reduced incidence rates for influenza, the common cold and severe cases of COVID-19, with diminished mortality rates for pneumonia and other viral and bacterial infections.

in lymphoid progenitors as demonstrated in clinical studies. ${ }^{15}$

Taken together, emerging data suggests that physical activity can have beneficial effects on the integrated immune response and provides a physiological basis for the role of exercise training to augment host defences against infections.

\section{EXERCISE AND INFECTIOUS DISEASE}

When exercise training is sustained for weeks and months, it may be postulated that the recurrent transient surge in circulating immune cells augments immunosurveillance against pathogens, lowers systemic inflammation, enhances antibody responses to vaccinations and reduces infectious disease morbidity and mortality. ${ }^{10-19}$ Figure 2 summarises the burgeoning evidence supporting a broad spectrum and beneficial effect of regular exercise training against viral and bacterial infections. ${ }^{10} 1218$ 20-23 Near-daily physical activity compared with inactivity has been linked to reduced incidence rates for influenza, the common cold and severe cases of COVID-19, with diminished mortality rates for pneumonia and other viral and bacterial infections in the general population. ${ }^{20-23}$

Multiple lines of experimental evidence support the hypothesis that moderate exercise may lower risk for respiratory infection in the general population. In a large epidemiological study of 97844 adults from England and Scotland, exercise training was associated with a lowering of the risk for bacterial and viral infectious disease mortality by more than $50 \%$ over a 9 -year period ${ }^{21}$ (figure 2). Acute respiratory illness (number of days ill during 12 weeks of the winter and fall seasons) was $43 \%$ lower in adults engaging in an average of 5 or more days per week of aerobic exercise compared with those who were largely inactive after accounting for confounders such as age, education level, marital status, gender, body mass index and perceived mental stress (figure 2).$^{22}$ Data from the UK Biobank showed that physical inactivity was related to a $32 \%$ increased risk for COVID-19 hospitalisations $^{23}$ (figure 2). The lifestyle combination of physical inactivity, cigarette smoking and obesity increased the risk of COVID-19 hospitalisation 4.4-fold compared with optimal lifestyles and accounted for up to $51 \%$ of the population attributable risk. Other data support reductions in incidence and mortality rates for influenza and pneumonia. ${ }^{2021}$

Long-term exercise training has also been shown in multiple studies to improve the immune response to influenza vaccination. ${ }^{10} 19$ Ongoing research will determine if physical activity augments the antibody and $\mathrm{T}$ cell response to COVID-19 vaccines, especially among the obese, elderly and subgroups if patients with arthritis who experience reduced vaccine efficacy. ${ }^{10} 1819$

These findings may be of particular clinical value for individuals with autoimmune inflammatory rheumatic diseases (AIIRD) who by virtue of complex 
Table 1 Exercise immunology training studies with RA participants

\begin{tabular}{|c|c|c|c|}
\hline Investigators & Study participants & Research design & Primary findings \\
\hline $\begin{array}{l}\text { Andersson et } \\
a l, 2020^{26}\end{array}$ & $\begin{array}{l}49 \text { older adults ( } \geq 65 \text { years) with } \\
\text { RA }\end{array}$ & $\begin{array}{l}\text { Randomised to } 20 \text { weeks of mixed } \\
\text { aerobic and resistance exercise } \\
\text { (supervised three sessions/week) or } \\
\text { control (home-based light exercise) } \\
\text { groups }\end{array}$ & $\begin{array}{l}\text { Despite improvements in aerobic } \\
\text { capacity and strength with supervised } \\
\text { exercise, no group differences for } \\
\text { DAS28, CRP or MDSCs. Proportions } \\
\text { of blood regulatory T and B cells } \\
\text { decreased with supervised exercise }\end{array}$ \\
\hline $\begin{array}{l}\text { Bartlett et al, } \\
2018^{27}\end{array}$ & $\begin{array}{l}12 \text { physically inactive older } \\
\text { adults (age } 64 \pm 7 \text { years) with } \\
\text { RA }\end{array}$ & $\begin{array}{l}\text { All participants, } 10 \text { weeks of high } \\
\text { intensity interval walk training (three } \\
\text { sessions/week, } 30 \mathrm{~min} / \text { session, } 10 \\
1 \text { min intense intervals); no control } \\
\text { group }\end{array}$ & $\begin{array}{l}\text { Aerobic capacity improved, with } 38 \% \\
\text { decrease in DAS28; improvement in } \\
\text { several measures of innate immune } \\
\text { function; no changed in CRP and } \\
\text { cytokines }\end{array}$ \\
\hline $\begin{array}{l}\text { Baslund et al, } \\
1993^{28}\end{array}$ & $\begin{array}{l}18 \text { adults with RA randomised } \\
\text { to training ( } 49 \pm 3 \text { years) and } \\
\text { control ( } 47 \pm 3 \text { years) groups }\end{array}$ & $\begin{array}{l}\text { Training group exercised on bicycle } \\
\text { ergometers for } 8 \text { weeks }(4-5 \\
\text { sessions/week, interval training with } \\
3 \times 5 \text { min intense intervals }\end{array}$ & $\begin{array}{l}\text { No group differences over time for } \\
\text { measures of T and NK cell function or } \\
\text { blood cytokine levels (IL-6, IL-1 } \alpha \text {, IL- } \\
1 \beta \text { ) }\end{array}$ \\
\hline $\begin{array}{l}\text { Rall et al, } \\
1996^{29}\end{array}$ & $\begin{array}{l}8 \text { adults with RA (ages } 25-65 \\
\text { years), } 8 \text { healthy young adults } \\
\text { (ages } 22-30 \text { years), } 14 \text { healthy } \\
\text { elderly adults (ages } 65-80 \\
\text { years) }\end{array}$ & $\begin{array}{l}\text { Participants with RA, young adults } \\
\text { and half of elderly adults trained for } \\
12 \text { weeks; progressive resistance } \\
\text { training, } 2 \text { sessions/week, } 5 \\
\text { exercises, } 3 \text { sets, } 8 \text { reps }\end{array}$ & $\begin{array}{l}\text { No group differences over time } \\
\text { for immune cell counts, cytokine } \\
\text { production, T cell proliferation or DTH } \\
\text { response. }\end{array}$ \\
\hline
\end{tabular}

CRP, C reactive protein; DAS28, disease activity score 28; DTH, delayed type hypersensitivity; IL, interleukin; MDSCs, myeloid derived suppressor cells; NK, natural killer; RA, rheumatoid arthritis.

dysfunctional immune changes from their underlying diseases compounded by immunosuppressive therapies and a high prevalence of comorbidities appear to be at increased risk of infectious complications including acute respiratory viral infections and severe outcomes in COVID-19. ${ }^{24}$ Importantly, the role of relative physical inactivity as a risk factor potentially contributing to these risks remains unexplored.

Few studies have assessed the effects of exercise on immunity in individuals with AIIRD and none have appraised the potential for exercise training to affect the incidence or severity of infectious diseases. In terms of assessing the effects of exercise on immune parameters, the results are mixed and disappointing given the large potential to shift biomarkers in the beneficial direction (table 1). ${ }^{26-29}$ Contributing factors include weak study designs and lack of control for numerous potential confounding factors. For example, the study by Bartlett et $a l^{27}$ with 12 physically inactive adults with rheumatoid arthritis (stable, no recent medication changes) showed that 10 weeks of high-intensity interval walking training reduced disease activity and improved several measures of innate immune function. The investigators speculated that exercise training may improve joint health by moving dysfunctional immune cells out of the joint, allowing for replacement with more functional immune cells. ${ }^{27}$ However, this study did not include a randomised control group and thus was unable to determine if changes were due to the exercise intervention or the passage of time. No meaningful changes occurred in $\mathrm{C}$ reactive protein or inflammatory cytokines, and the authors recommended that aerobic training should be combined with weight loss to reduce inflammation biomarkers. ${ }^{27}$

Recent reviews have concluded that existing data do not support that AIIRD-induced increases in inflammation or disease activity can be countered through exercise training despite improvements in exercise capacity, physical function and quality of life. ${ }^{30}{ }^{31}$ Improvement in immune and inflammation biomarkers with exercise training in individuals with AIIRD may require higher exercise workload volumes and significant weight loss that exceed what they are willing or capable of achieving. ${ }^{27}$

\section{Barriers to physical activity in rheumatic diseases}

Despite evidence of the beneficial effects of physical activity on general health and well-being there are numerous barriers which account for the low level of physical activity in patients with arthritis and allied conditions that must be overcome. ${ }^{3}$ These include disease specific factors including joint damage, pain and fatigue in many patients which may require active engagement and accommodation and at times lowering goals which may begin with reducing sedentary habits with the "move more sit less' approach. Psychological and perceptual barriers must be addressed as well and educating patients on both the broad benefits of physical activity as well as the potential for exercise to enhance immune defences may be empowering. Perhaps most impactful, and emphasised in the 2018 EULAR guidelines for physical activity in people with inflammatory arthritis and osteoarthritis, ${ }^{3}$ is emphasising the importance and responsibility of physicians and advanced practitioners and not just physical 
therapists and physiatrists, to promote physical activity to our patients by educating them on its broad beneficial effects. A recent review of the benefits and promotion of physical activity in rheumatoid arthritis suggests that our patients are not getting the message. ${ }^{32}$ Finally physicians and other providers are in need of education to enhance their confidence to counsel and instruct their patients on evidence based guidelines for physical activity as well as general wellness behaviours.

\section{RESEARCH DIRECTIONS}

The increased susceptibility to infections in individuals with AIIRD is likely due to an admixture of factors including an underlying complex dysfunctional autoreactive immune system compounded by physical inactivity, obesity and immunosuppressive and anti-inflammatory therapies. The failure of exercise interventions to impact immune parameters in clinical studies summarised in table 1 likely reflects limitations of trial design and crude outputs as well as the difficulty of controlling for the above noted putative confounders in randomised trials. Studies assessing the incidence and severity of infections in patients with AIIRD must also begin to assess and control for levels of physical activity and training.

The multifaceted nature of AIIRD may demand a human systems biology approach using metabolomics, proteomics, lipidomics, genomics, epigenetics and microbiomics. Immunometabolism links cellular metabolism and immunology and has shown that disease states can be traced to alterations in the bioenergetic metabolism of immune cells. ${ }^{14}$ These approaches are increasingly being applied in the field of exercise immunology and offer a more integrated approach to improve understanding of how exercise influences the immune system and impacts health, the ageing process and susceptibility to infectious disease. ${ }^{1014}$

These emerging omics technologies have the potential to more clearly define underlying mechanisms and adjust for multiple types of lifestyle and therapy interventions with patients with AIIRD. These types of studies resource intensive and require sensitive mass spectrometry platforms with thousands of chemical standards, rigorous sample extraction and processing procedures, precise quality control and identification protocols and sophisticated bioinformatics support but are being increasingly incorporated in the field. ${ }^{14}$

\section{CONCLUSION}

Regular physical activity can be viewed as an important immune system adjuvant to stimulate the trafficking of distinct and highly active immune cell subtypes between the circulation and tissues. ${ }^{10}$ With near daily exercise, these acute changes operate through a summation effect to enhance immune defence activity against a variety of pathogens and overall metabolic health. Randomised clinical trials and epidemiological studies consistently support the inverse relationship between moderate exercise training and incidence of acute respiratory infections including the common cold, influenza, pneumonia and COVID-19. Regular exercise training has numerous effects on the integrated immune response with evidence supporting an overall anti-inflammatory effect, especially when combined with weight loss and the summation of these changes may potentially provide meaningful clinical benefits for individuals with AIIRD. Future studies using a multiomics and humans systems biology approach may reveal heretofore undiscovered benefits.

\section{Contributors Both authors contributed equally.}

Funding The authors have not declared a specific grant for this research from any funding agency in the public, commercial or not-for-profit sectors.

Competing interests None declared.

Patient consent for publication Not required.

Provenance and peer review Commissioned; externally peer reviewed.

Open access This is an open access article distributed in accordance with the Creative Commons Attribution Non Commercial (CC BY-NC 4.0) license, which permits others to distribute, remix, adapt, build upon this work non-commercially, and license their derivative works on different terms, provided the original work is properly cited, appropriate credit is given, any changes made indicated, and the use is non-commercial. See: http://creativecommons.org/licenses/by-nc/4.0/.

\section{ORCID iD}

Leonard Calabrese http://orcid.org/0000-0002-1789-4923

\section{REFERENCES}

1 Bull FC, Al-Ansari SS, Biddle S, et al. World Health organization 2020 guidelines on physical activity and sedentary behaviour. Br J Sports Med 2020;54:1451-62.

2 U.S. Department of Health and Human Services. Physical activity guidelines for Americans. 2nd edition. Washington, DC: U.S. Department of Health and Human Services, 2018.

3 Rausch Osthoff A-K, Niedermann K, Braun J, et al. 2018 EULAR recommendations for physical activity in people with inflammatory arthritis and osteoarthritis. Ann Rheum Dis 2018;77:1251-60.

4 Hernández-Hernández MV, Díaz-González F. Role of physical activity in the management and assessment of rheumatoid arthritis patients. Reumatol Clin 2017;13:214-20.

5 Thompson WR, Sallis R, Joy E, et al. Exercise is medicine. Am J Lifestyle Med 2020;14:511-23.

6 Physical activity guidelines Advisory Committee. 2018 physical activity guidelines Advisory Committee scientific report. 2018. Washington, DC: U.S. Department of Health and Human Services, 2018.

7 Lavie CJ, Ozemek C, Carbone S, et al. Sedentary behavior, exercise, and cardiovascular health. Circ Res 2019;124:799-815.

8 Hwang C-L, Chen S-H, Chou C-H, et al. The physiological benefits of sitting less and moving more: opportunities for future research. Prog Cardiovasc Dis 2021;Jan 13:S0033-0620:00003-7.

9 Metsios GS, Kitas GD. Physical activity, exercise and rheumatoid arthritis: effectiveness, mechanisms and implementation. Best Pract Res Clin Rheumatol 2018;32:669-82.

10 Nieman DC, Wentz LM. The compelling link between physical activity and the body's defense system. $J$ Sport Health Sci 2019;8:201-17.

11 Simpson RJ, Campbell JP, Gleeson M, et al. Can exercise affect immune function to increase susceptibility to infection? Exerc Immunol Rev 2020;26:8-22.

12 Nieman DC. Coronavirus disease-2019: a tocsin to our aging, unfit, corpulent, and immunodeficient Society. J Sport Health Sci 2020;9:293-301.

13 Filgueira TO, Castoldi A, Santos LER, et al. The relevance of a physical active lifestyle and physical fitness on immune defense: mitigating disease burden, with focus on COVID-19 consequences. Front Immunol 2021;12:587146.

14 Nieman DC, Pence BD. Exercise immunology: future directions. $J$ Sport Health Sci 2020;9:432-45.

15 Duggal NA, Niemiro G, Harridge SDR, et al. Can physical activity ameliorate immunosenescence and thereby reduce age-related multi-morbidity? Nat Rev Immunol 2019;19:563-72. 
16 Rooney BV, Bigley AB, LaVoy EC, et al. Lymphocytes and monocytes egress peripheral blood within minutes after cessation of steady state exercise: a detailed temporal analysis of leukocyte extravasation. Physiol Behav 2018;194:260-7.

17 Shen B, Tasdogan A, Ubellacker JM, et al. A mechanosensitive peri-arteriolar niche for osteogenesis and lymphopoiesis. Nature 2021;591:438-444. Epub ahead of print. PMID.

18 Nieman DC. Exercise is medicine for immune function: implication for COVID-19. Curr Sports Med Rep. In Press 2021.

19 Valenzuela PL, Simpson RJ, Castillo-García A, et al. Physical activity: a coadjuvant treatment to COVID-19 vaccination? Brain Behav Immun 2021;94:00105-7.

20 Wu S, Ma C, Yang Z, et al. Hygiene behaviors associated with influenza-like illness among adults in Beijing, China: a large, population-based survey. PLoS One 2016;11:e0148448.

21 Hamer M, O'Donovan G, Stamatakis E. Lifestyle risk factors, obesity and infectious disease mortality in the general population: linkage study of 97,844 adults from England and Scotland. Prev Med 2019;123:65-70.

22 Nieman DC, Henson DA, Austin MD, et al. Upper respiratory tract infection is reduced in physically fit and active adults. $\mathrm{Br} J$ Sports Med 2011;45:987-92.

23 Hamer M, Kivimäki M, Gale CR, et al. Lifestyle risk factors, inflammatory mechanisms, and COVID-19 hospitalization: a community-based cohort study of 387,109 adults in UK. Brain Behav Immun 2020;87:184-7.

24 Wang Q, Liu J, Shao R, et al. Risk and clinical outcomes of COVID-19 in patients with rheumatic diseases compared with the general population: a systematic review and meta-analysis. Rheumatol Int 2021;41:851-61.

25 Kilian A, Chock YP, Huang IJ, et al. Acute respiratory viral adverse events during use of antirheumatic disease therapies: a scoping review. Semin Arthritis Rheum 2020;50:1191-201.

26 Andersson SEM, Lange E, Kucharski D, et al. Moderate- to high intensity aerobic and resistance exercise reduces peripheral blood regulatory cell populations in older adults with rheumatoid arthritis. Immun Ageing 2020;17:12.

27 Bartlett DB, Willis LH, Slentz CA, et al. Ten weeks of high-intensity interval walk training is associated with reduced disease activity and improved innate immune function in older adults with rheumatoid arthritis: a pilot study. Arthritis Res Ther 2018;20:127.

28 Baslund B, Lyngberg K, Andersen V, et al. Effect of 8 wk of bicycle training on the immune system of patients with rheumatoid arthritis. J Appl Physiol 1993;75:1691-5.

29 Rall LC, Roubenoff R, Cannon JG, et al. Effects of progressive resistance training on immune response in aging and chronic inflammation. Med Sci Sports Exerc 1996;28:1356-65.

30 Metsios GS, Moe RH, Kitas GD. Exercise and inflammation. Best Pract Res Clin Rheumatol 2020;34:101504.

31 Benatti FB, Pedersen BK. Exercise as an anti-inflammatory therapy for rheumatic diseases-myokine regulation. Nat Rev Rheumatol 2015;11:86-97.

32 Katz P, Andonian BJ, Huffman KM. Benefits and promotion of physical activity in rheumatoid arthritis. Curr Opin Rheumatol 2020;32:307-14. 